\title{
Managing complications of percutaneous tracheostomy and gastrostomy
}

\author{
Aline N. Zouk, Hitesh Batra \\ Division of Pulmonary, Allergy, and Critical Care Medicine, The University of Alabama at Birmingham, Birmingham, AL, USA \\ Contributions: (I) Conception and design: Both authors; (II) Administrative support: Both authors; (III) Provision of study materials or patients: \\ Both authors; (IV) Collection and assembly of data: Both authors; (V) Data analysis and interpretation: Both authors; (VI) Manuscript writing: Both \\ authors; (VII) Final approval of manuscript: Both authors. \\ Correspondence to: Aline N. Zouk, MD. Division of Pulmonary, Allergy, and Critical Care Medicine, The University of Alabama at Birmingham, 1900 \\ University Blvd, THT 422, Birmingham, AL 35294, USA. Email: azouk@uabmc.edu.
}

\begin{abstract}
Percutaneous tracheostomy and gastrostomy are some of the most commonly performed procedures at bedside in the intensive care unit. While they are generally considered safe, they can be associated with numerous short and long-term complications, many of which can occur long after their placement and cause significant morbidity. Performers of these procedures should possess a comprehensive understanding of procedural indications and contraindications, and know how to recognize and manage complications that may arise. In this review, we highlight complications of percutaneous tracheostomy and describe strategies for their prevention and management, with a special focus on post-tracheostomy tracheal stenosis. Other complications reviewed include bleeding, pneumothorax and subcutaneous emphysema, posterior wall injury, tube displacement, tracheomalacia, tracheoinominate artery fistula, tracheo-esophageal fistula, and stomal cellulitis. Gastrostomy complications and their management are also discussed including bleeding, internal organ injury, necrotizing fasciitis, aspiration pneumonia, buried bumper syndrome, tumor seeding, wound infection, tube displacement, peristomal leakage, and gastric outlet obstruction. In light of the potentially serious outcomes associated with complications of percutaneous tracheostomy and gastrostomy, the emphasis should be placed on risk-reduction strategies to minimize morbidity and mortality. We therefore present detailed pragmatic and comprehensive checklists to serve as a reference for clinicians involved in performing these procedures.
\end{abstract}

Keywords: Percutaneous tracheostomy; percutaneous endoscopic gastrostomy; complications; tracheal stenosis

Submitted Mar 13, 2020. Accepted for publication Aug 05, 2020.

doi: $10.21037 /$ jtd-19-3716

View this article at: http://dx.doi.org/10.21037/jtd-19-3716

\section{Introduction}

Tracheostomy is one of the oldest surgical procedures in medical history and reference to this technique can be found dating 3,500 years ago (1). Percutaneous dilatational tracheostomy (PDT) has evolved substantially since its first description in 1957 and later modification in 1985 by Ciaglia (2). It is a commonly performed procedure at bedside in the intensive care unit, with over 100,000 performed annually in the United States alone (3).

The Ciagla Blue Rhino (CBR) method uses a modified
Seldinger technique where a single dilation using a tapered hydrophilic coated dilator is performed under bronchoscopic visualization (4). It is the most commonly utilized procedure technique for PDT, and has become the standard of care against which other techniques are tested in the $21^{\text {st }}$ century.

Despite its acceptance worldwide as the procedure of choice for tracheostomy, PDT can be associated with major complications, including death. Each year, approximately 500 patients in the United States die or are permanently disabled because of a tracheostomy (5). In a meta-analysis of 
8,324 PDT cases, the estimated procedure related morality was $2.18 \%$, and of these $31 \%$ were intra-procedural fatalities and $49 \%$ with early mortality within seven days of the procedure (6). The incidence of late complications is estimated to be as high as $65 \%$ of patients (7).

This procedure has been adopted by multiple subspecialties including otorhinolaryngologists, interventional pulmonologists, thoracic surgeons, intensivists, anesthesiologists, and trauma surgeons. Although no formal surgical training is needed, performers of PDT should be appropriately trained in advanced airway management and emergent airway techniques, possess a comprehensive understanding of procedural indications and contraindications, and know how to recognize and manage complications that may arise (4).

In this review, we will highlight complications of PDT and describe management strategies, with a special focus on post-tracheostomy tracheal stenosis (PTTS). In the latter part of this review, we describe the major and some minor complications, including strategies for their prevention and management.

\section{Complications of PDT}

Studies are lacking in this field with the majority of data derived from retrospective and cohort studies rather than prospective, randomized controlled trials. Only few short series have analyzed long term complications. One of the greatest impediments to understanding complications of PDT is the lack of standardization of the definitions of complications and their mode of assessment. Furthermore, the characteristics of critically ill patients make longitudinal studies hard to conduct due to early death or lost to followup in long term acute care facilities. The time course of various complications is highly variable. Complications such as tracheal stenosis, granulation tissue formation, or tracheomalacia from traumatic intubation or excessive cuff pressures can occur in as little as 1 to 14 days (7). Tracheal stenosis can occur months, or even years after and may be under-reported when it fails to yield clinically detectable symptoms. It is often difficult to differentiate these from complications of prior prolonged endotracheal intubation.

\section{Perioperative and early complications}

\section{Bleeding}

Bleeding is the most common early complication of tracheostomy (6), with an estimated incidence of 0.6-5.0\% (8).
Early bleeding within 48 hours of the procedure is usually minor and comes from superficial veins (9). A more serious cause of hemorrhage from a tracheoinominate artery fistula usually occurs later and will be discussed in the latter part of this review. Several pre-procedural measures such as use of ultrasound to detect abnormal vascular anatomy and identify major superficial veins may help avoid injury to vessels (6). Reversal of underlying coagulopathy and administration of desmopressin in uremic patients prior to procedure can minimize bleeding risk (4). During tracheostomy placement, using lidocaine with epinephrine for local anesthesia, making a small incision at the entry site, and securing the neck plate firmly around tracheostomy tube can also minimize bleeding (4).

Intra-operative tracheal hemorrhage can be lifethreatening, even if the actual blood loss is low. In patients with respiratory failure and already a low pulmonary reserve, even 150-200 $\mathrm{mL}$ of blood in the trachea can lead to severe hypoxia and inability to ventilate. Additionally, with flexible bronchoscopy, even small amounts of blood can significantly reduce visibility, as suction capacity is quite low. Therefore, intra-tracheal bleeding during PDT placement should trigger the algorithm to immediately secure the airway (10).

In the case of minor bleeding around the stoma, local pressure and packing with hemostatic gauze pads soaked in adrenaline or tranexamic acid can help achieve hemostasis (11). If bleeding or oozing persists around the tracheostomy site, the stoma may need to be explored to locate and cauterize or suture the bleeding vessel (11).

\section{Pneumothorax and subcutaneous emphysema}

Pneumothorax and subcutaneous emphysema are well described complications of PDT, with an estimated incidence of $0.8 \%$ and $1.4 \%$, respectively (12). Deaths from tension pneumothorax or bilateral pneumothoraces posttracheostomy have been described in the literature (6). Operator inexperience, chronic obstructive pulmonary disease, obesity and anatomic spine abnormalities place patients at a higher risk for complications (6). Furthermore, malpositioning of tracheostomy tube inside the stoma, prolonged operative times in difficult procedures, and dissection of anterior neck tissue in obese patients can cause excessive air leak into subcutaneous tissue (12).

The role of bronchosocopy in preventing pneumothorax remains controversial. While the use of bronchoscopy can reduce this complication by confirming that the guidewire and guiding catheter are inserted intratracheally $(1,6,13)$, the 
complete or almost complete tracheal occlusion by dilators or bronchoscope can cause air trapping and overinflation by valve effect, leading to an increased risk of barotrauma (14). This can be avoided by using a bronchoscope with O.D. (outer diameter) at least $2 \mathrm{~mm}$ less than the I.D. (inner diameter) of the endotracheal tube, neuromuscular blockade (4), and ventilation with lower pressures, smaller tidal volumes, and higher respiratory rates $(14,15)$.

\section{Tracheal wall perforation}

Difficult insertions requiring increased amount of pressure to insert the tracheostomy tube have been associated with mechanical trauma and injury to the tracheal wall. This excessive force can cause dilator advancement over the bolstering catheter intra-tracheally onto the guidewire. The guidewire alone cannot provide enough support to keep the dilator within the trachea and therefore predisposes to perforation of the posterior tracheal wall during the procedure (1). Guidewire kinking has been associated with this phenomenon and if seen should therefore raise suspicion for posterior wall injury $(1,16)$. The incidence of tracheal wall perforation is reported as $<1 \%$, but this may be an underestimation as most studies reporting the complications associated with PDT have not included bronchoscopic evaluation of the airway (1).

Stabilization of the guidewire and guiding catheter is a critical step to avoid posterior wall injury and barotrauma. Some authors even advocate for the use of a two-person technique where one operator performs the tracheostomy and the other is dedicated to stabilizing the guidewire and catheter (1). Most PDT kits, including the Ciaglia Percutaneous Tracheostomy Introducer Set, have now undergone modifications to include a ridge on the distal end, preventing the dilator from advancing over the catheter $(1,6)$.

In the past, surgical repair of tracheal tears was the treatment of choice for any tracheal tear (17). Although there are no clear guidelines in place, there is increasing evidence suggesting conservative management as a safe alternative, as most tears self-resolve (17-19). The decision for treatment depends on characteristics of tracheal lesion such as location, length, depth, and the patient's clinical condition. Non-surgical management can be used in clinically stable patients with small tears $<2 \mathrm{~cm}(17,20)$ in the upper two-thirds of the trachea $(21,22)$, with minimal non-progressing subcutaneous emphysema or pneumomediastinum $(17,23)$, and no esophageal injury (24), respiratory distress (21), or mediastinitis (21), and imminent extubation. Similarly, tears not involving all tracheal layers are also suitable for conservative management (22). More recently, stent placement with silicone stents has gained traction as an alternative to surgical therapy, especially in non-operable candidates (25-27). Stent placement will be discussed in greater detail later in this review. Immediate surgical repair is indicated in patients with concomitant esophageal injury or mediastinitis (18).

\section{Early tube displacement, accidental decannulation, and paratracheal insertion}

The incidence of tracheostomy tube displacement is $1.5 \%$ (11). While uncommon, accidental tube displacement can be life-threatening if occurring early after PDT before track maturation. In the first 3-5 days post-PDT placement, the immaturity of the stomal tract can risk loss of the airway. Placement of endotracheal tube into the tracheal stoma to save the airway should be avoided, as the endotracheal tube can inadvertently be inserted paratracheally into a false track, especially in obese patients whose skin to trachea distance is $>2-4 \mathrm{~cm}$ (28). Orotracheal intubation is therefore recommended, with the cuff inflated distal to the stoma. After securing an airway and stablizing the patient, the stoma can then be redilated and the tube replaced in a controlled setting, preferably under bronchoscopic guidance $(29,30)$.

Suturing of the neck plate can minimize accidental decannulation and airway loss. Restricting the first tube change to after 7 days and using a guiding catheter during tracheal exchange can minimize paratracheal insertion $(4,6,28)$. Additionally, the use of extra-long tracheostomy tubes in obese patients with short necks avoids malposition of tracheostomy tube and reduces incidence of airway loss (31).

Lastly, the development of a dedicated 'crisis' plan, the immediate availability of the required equipment in case of airway loss, and periodic staff training have been proposed to help reduce the grave outcomes of this potentially fatal complication (32).

\section{Late complications}

\section{Post-tracheostomy tracheal stenosis (PTTS)}

PTTS, the abnormal narrowing of tracheal lumen from fibrosis or granulation tissue formation after PDT placement, is perhaps the most common complication $(7,33)$ (Figure 1). While most patients develop some degree of tracheal narrowing at the site of tracheostoma, only $3-12 \%$ develop clinically significant stenosis and require 

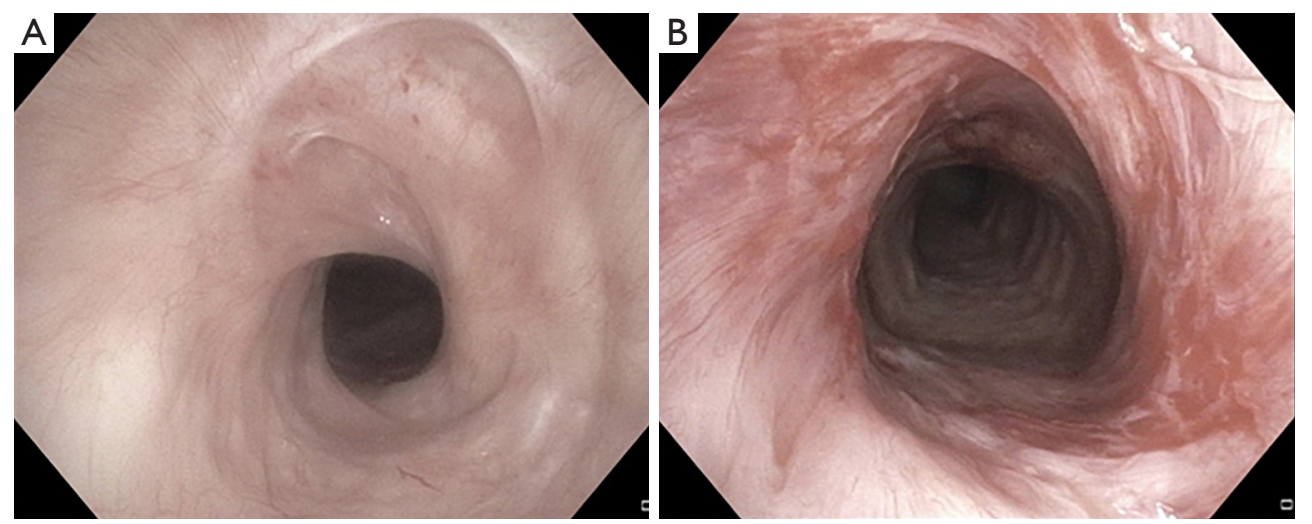

Figure 1 Complex tracheal stenosis $>1 \mathrm{~cm}$ in length with anterior wall damage proximally and web-like stenosis distally. (A) Pre-dilation; (B) post-dilatation.

interventions $(7,33)$.

In the early stages, this may present as failure to wean off the ventilator with high peak airway pressures or difficulty passing suction catheter (7). In the later stages, PTTS may manifest as a failure to decannulate, upper-airway obstruction with dyspnea or stridor, or even respiratory failure after decannulation.

While some stenoses may remain subclinical, symptoms generally emerge when the lumen reaches $<50 \%$ of its original diameter, causing cough and difficulty in clearing secretions. Exertional dyspnea occurs once the airway diameter is reduced to $<10 \mathrm{~mm}$, with stridor at $<5 \mathrm{~mm}$ stenosis (34).

Multiple predisposing factors for the development of PTTS have been described in the literature including: high tracheostomy site, traumatic or prolonged intubation, history of prior intubation or tracheostomy, excessive corticosteroid steroid usage, advanced age, female sex, severe reflux disease, autoimmune diseases, obstructive sleep apnea, and local radiation therapy for oropharyngeal and laryngeal cancer $(33,35)$.

PTTS can occur at various levels within the tracheaeither at the level of the stoma, the cuff site, or the tracheostomy tube's distal tip. Stenosis at the stomal level occurs due to bacterial infection and chondritis which weakens the anterior and lateral tracheal walls, causing focal malacia. Obstructive granulation tissue from abnormal tissue repair can also develop and cause scarring around the stoma. Traumatic injury at the time of placement can also lead to stenosis due to rupture or displacement of tracheal rings. These stenoses are usually triangular in shape, termed "A-shaped" or "A-frame" strictures $(36,37)$.
Stenosis at the cuff is usually occurs due to overinflation of cuff causing excessive cuff pressures that exceed the perfusion pressure of tracheal wall capillaries, causing focal ischemia. These circular mucosal erosions or pressure sores begin as tracheitis and mature into circumferential scars and stenoses (36). Stenosis at the tube tip is caused by prolonged impingement of the posterior, and rarely anterior, tracheal wall by the distal tip. The recurrent injury and irritation leads to granulation tissue formation, which can ultimately lead to tracheal stenosis and tube obstruction $(7,36)$.

Despite the frequency of PTTS, treatment strategies are not well defined, with no published guidelines or rigorous randomized controlled trials to guide management. A multidisciplinary approach is crucial, with collaboration between otolaryngologists, interventional pulmonologists, and thoracic surgeons being the key to success.

Surgical approach is the preferred treatment modality in symptomatic patients with PTTS, where the stenotic area is surgically resected followed by end-to-end reanastomosis. This is especially true for complex and recurrent stenoses. Surgical resection carries a not insignificant rate of morbidity and mortality. While some highly specialized and experienced centers report a mortality rate of $1.8 \%$ (38), others have found rates up to $5 \%$. Morbidity related to restenosis, granuloma formation around the suture site, infections and bleeding occur in up to $14 \%$ of cases $(35,39)$. Anastomosis within the cricoid or thyroid cartilage have poorer wound healing profiles (36).

Bronchoscopy prior to surgery is performed to evaluate the airway, restore patency as a bridge to surgery, and facilitate ventilation during surgery. In many cases, however, surgical approach may be contraindicated due 
to severe comorbidities, high subglottic stricture location, or long vertical extent of $>4-6 \mathrm{~cm}$ (37). In these patients, interventional bronchoscopy procedures can offer a less invasive option for definitive treatment, with success rates ranging from $32-66 \%$ (40). In emergency situations such as acute obstruction of airway, therapeutic bronchoscopic techniques to quickly stabilize the airway is the management of choice.

Several factors are considered when forming individualized treatment plans in patients with PTTS, including the location, severity, morphology and extent of stenosis, as well as swallowing dysfunction and degree of other functional impairment caused by stenosis $(23,36,37,41)$. Light bronchoscopy is used to define the exact site (whether supraglottic, glottic, subglottic, tracheal or combined), etiology, complexity, focality, and degree of airway lumen obstruction $(7,36,37)$. It also allows for precise measurements of the vertical length of stenosis and its location relative to vocal cords, cricoid and main carina (37). Optical coherence tomography (OCT) and radial probe endobronchial ultrasound can provide cross-sectional imaging of the airway wall and aid in the evaluation of inflammation of surrounding mucosa. However, these modalities are not routinely used in clinical practice and require larger studies confirming their usefulness $(36,37)$. The qualitative and quantitative measurements obtained from bronchoscopy are crucial for determining candidacy for surgical versus endoscopic approaches, as stricture complexity and length are perhaps the most important predictors of outcomes after either intervention $(36,37,41)$.

Depending on severity and duration of pressure injury, either weblike short stenosis or hourglass long stenosis with destruction of entire wall can form. Simple stenoses are short, $<1 \mathrm{~cm}$ strictures that are restricted to mucosal disease with no damage to the underlying cartilage and no associated malacia (36). These are often weblike, and can be either eccentric or circumferential, with poorer outcomes associated with the latter (38). Mechanical dilation with a rigid bronchoscope or balloon tracheoplasty alone or in combination with radial incisions using thermal techniques such as electrocautery, carbon dioxide $\left(\mathrm{CO}_{2}\right)$ or Neodymium-doped yttrium aluminum garnet (Nd-YAG) laser or APC (Argon Plasma Coagulation), is the treatment of choice, with success rate as high as $66-95 \%$ after $1-3$ sessions $(38,40)$.

Spray cryotherapy (SC) is a new modality being used in the treatment of tracheal stenosis. By causing minimal disruption of the extracellular matrix, SC allows for more appropriate wound repair, resulting in a more physiological healing process and minimizing further mucosal injury. With less fibrosis and long-term scarring, the need for re-interventions may be reduced and symptom-free time between procedures is prolonged (42). Compared to contact cryotherapy, SC has a more even and linear distribution of the cryogen over a larger area, therefore improving its efficacy (43).

Topical application of Mitomycin $\mathrm{C}$ can serve as adjunct to mechanical debridement or dilation. Mitomycin $\mathrm{C}$ is anti-proliferative agent that inhibits collagen formation by fibroblasts and delays re-epithelialization $(35,39,43,44)$. Small pledgets soaked in Mitomycin C $(0.4-2 \mathrm{mg} / \mathrm{mL})$ are applied to the stenotic region radially using rigid forceps for 1-2 minutes at a time, for a total of around 10 minutes. Improved outcomes are seen when several applications are given 3-4 weeks apart rather than a single application, with delayed time to repeat dilations in complex stenoses $(35,39)$.

Complex stenoses are often long $(>1 \mathrm{~cm})$, hourglass shaped, and are associated with intramural disease and destruction of tracheal wall causing concomitant malacia. While simple-web like stenoses can often be cured using mechanical dilation, bronchoscopic therapies are less effective in complex stenoses, with a high failure rate of $>30 \%$. For example, rigid bronchoscopy with dilation alone has a $90 \%$ relapse rate in complex stenosis $(36,45)$. Surgery when possible, therefore remains the gold standard for treatment.

Bronchoscopic dilation with or without stent placement can be performed as a potential bridge to surgery or as a definitive long-term palliative treatment option when surgery is not possible. As a general rule, stent insertion should be used as a last therapeutic resort as it can further injure the airway and exacerbate potentially resectable disease (37). Silicone stents are recommended for benign strictures of PTTS (46) as self-expandable metallic stents are associated with extensive granulation tissue formation and higher risk of stent fracture or airway perforation upon removal (37). A meta-analysis of 24 studies by Murgu et al. showed that while initial outcomes are good, success rates for tracheal remodeling and achieving lumen patency after stent removal is low at $17.6 \%$ after 6 months and $46.8 \%$ after 12 months (37). Predictors of success of stent insertion include stenoses $<1 \mathrm{~cm}$ in vertical extent and stenoses without associated malacia (47).

There are no guidelines or criteria for timing of stent removal as the timing of cartilage regeneration without recurrence of stenosis is not always known (37). 

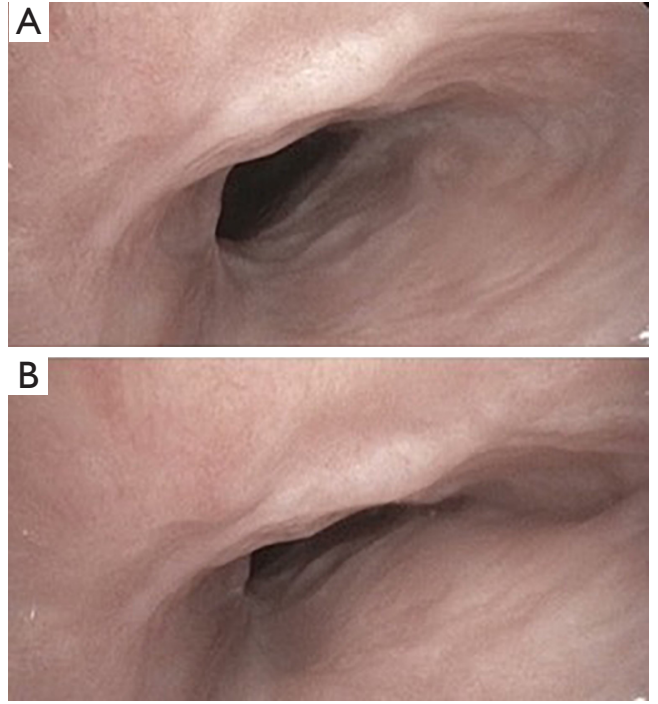

Figure 2 Complex trachel stenosis with tracheomalacia. (A) During inspiration; (B) anterior and posterior wall collapse during expiration.

The recommended stenting period, however, ranges from 6-18 months, depending on the degree of tracheal lesions, as full thickness lesions require longer period for stabilization $(39,46)$. In severe circumferential stenoses with tracheomalacia, at least 2 years of stenting has been proposed by Puma et al. (48). Following stent removal, routine surveillance bronchoscopic evaluation is crucial for evaluating residual or recurrent tracheal stenosis or tracheomalacia. Individualized treatment plans should be made based on clinical symptoms, bronchoscopic evaluation, and the patient's overall performance status. For example, residual tracheal stricture may be tolerated by patients with decreased physical activity (46).

Novel techniques including tracheal implantation of a cartilage graft (49), transplantation with an aortic allograft (50), and transplantation of a tissue engineered cadaveric airway (51) have been proposed as alternatives to tracheal sleeve resection or laryngotracheal reconstruction, but these approaches need further larger studies (37).

\section{Tracheomalacia}

Tracheomalacia is the weakening of tracheal wall causing excessive expiratory collapse of trachea. This results from ischemic injury to trachea leading to chondritis and subsequent necrosis and destruction of supporting cartilage. This loss of airway support causes collapse of the tracheal airway during expiration, resulting in expiratory flow limitation, air trapping and retained secretions (52-54). In post-tracheostomy patients, this often occurs concomitantly with tracheal stenosis as a combination of fixed stenosis and malacia (Figure 2). It can manifest as either failure to wean from mechanical ventilation in the acute setting, or progressive dyspnea and cough in patients with a history of tracheostomy (7).

In patients with current tracheostomy tube, placement of a longer tracheostomy tube to bypass area of expiratory collapse is the recommended approach (7). In decannulated patients, management differs based on severity of symptoms and expiratory airway collapse. In mild cases, a conservative approach with non-invasive positive pressure ventilation is a reasonable initial strategy, with pressure settings determined during bronchoscopic titration (37). In more severe cases, surgical options such as tracheosplasty or tracheal resection and reanastomosis may be considered if conservative management has failed (7). Similar to treatment of tracheal stenosis, silicone stent placement may be considered when surgery is unsafe or not feasible (37).

\section{Tracheoinominate artery fistula (TIF)}

Hemorrhage from TIF is a rare, but devasting complication of PDT, and occurs in $<1 \%$ of all cases $(4,7)$. It is the still the most common cause of death, and a true medical emergency, with mortality approaching $80-100 \%(6,7)$. In most cases, mild self-limited bleeding first occurs 1-6 weeks post-tracheostomy as a "sentinel bleed" followed by sudden massive hemoptysis several hours later $(6,7,28,30)$.

Overinflation of the tracheostomy cuff can lead to focal ischemic necrosis with damage to tracheal mucosa and eventual erosion into innominate artery $(7,55,56)$. Low tube placement below the third tracheal ring, which often occurs with procedures done without bronchoscopic guidance, can further increase this risk as the innominate artery crosses at tracheal rings $9-12$, or $4-8 \mathrm{~cm}$ below cricoid $(4,7,54)$. The inferior concave surface of cannula may then erode into the artery causing TIF (7). Other risk factors associated with TIF formation include repetitive head movements or excessive movement of tracheostomy $(4,7)$, concomitant radiotherapy (6), and the presence of coagulopathies (6).

Immediate surgical repair of the innominate artery is imperative (7). For stablization prior to surgery, the tracheostomy tube should be removed and the patient intubated endotracheally with the cuff inflated distal to bleeding source (4). Digital tamponade by placing finger in stoma and applying pressure to the anterior wall should be performed during transport to surgery $(4,28,57)$. 


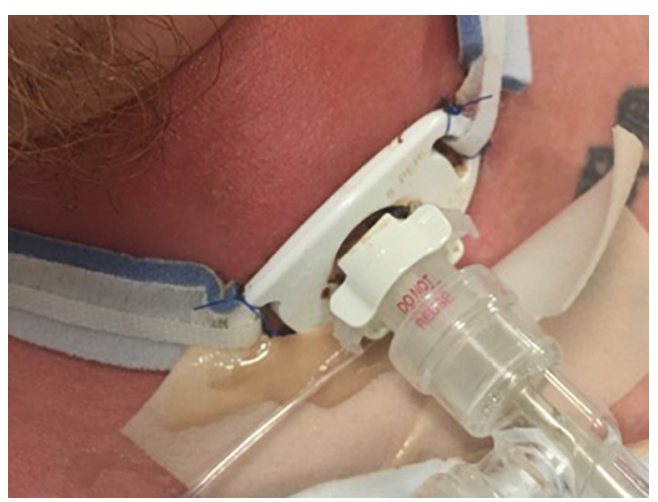

Figure 3 Cellulitis of stoma with purulent drainage.

Given the high mortality rate despite surgical repair, the best treatment strategy is to avoid this complication (7) by ensuring low cuff pressures $<25 \mathrm{mmHg}$, inserting tracheostomy above the $3^{\text {rd }}$ tracheal ring, and removing the tracheostomy tube as soon as indicated (4). Avoiding prolonged or extreme hyperextension of neck to prevent excessive downward pulling of the tube can also relieve pressure against anterior tracheal wall (7).

\section{Tracheoesophageal fistula (TEF)}

TEF, the development of a connection between the trachea and esophagus, is an extremely rare complication that occurs in $<1 \%$ of patients (7). In a review of 1,130 PDTs, while the incidence of TEF was $0.08 \%$, the development of this complication was universally fatal (11). This manifests as copious often bilious secretions through tracheostomy, recurrent aspiration of food, increased dyspnea, persistent cuff leak, or severe gastric distention as air goes from the trachea to stomach through the fistula (53).

TEF is usually iatrogenic as a result of injury to posterior wall during PDT, overinflation of tracheostomy cuff causing increased pressure and necrosis of tracheal wall, or erosion of tip of tracheostomy tube causing posterior wall injury $(7,58)$. Nasogastric tubes can lead to irritation and subsequent esophageal injury, further increasing the risk of TEF formation $(54,59)$. The widespread use of high-volume, low-pressure cuffed tracheostomy tubes has significantly decreased the incidence of TEF and other cuff related complications. The placement of small tracheostomy tubes necessitating over-inflation of the cuffs to provide adequate airway seal remains the most common cause of TEF (60).

Spontaneous closure of TEF is rare, and surgical repair is the definitive treatment $(59,61)$. The initial management of TEF however depends on the size of defect, level of ventilatory support needed, and clinical stability of the patient. TEFs that are small and not associated with significant air leaks, bleeding, or mediastinitis can initially be managed conservatively to delay surgery until the patient can be successfully weaned from mechanical ventilation. This includes exchanging the tracheostomy tube for one with a longer phlange with the cuff positioned below the fistula, adjusting ventilator settings to minimize airway pressures, and replacing any existing nasogastric tube with percutaneous gastrostomy feeding tube $(62,63)$. Endotracheal stenting with silicone or metallic stent can also used as a temporizing measure until clinical stability is achieved, making sure to slightly undersize the stent to avoid further stress on tracheal wall. In decompensating patients, urgent surgical esophageal repair is recommended (60).

\section{Stomal infection and cellulitis}

The tracheal stoma is at constant threat of infection and cellulitis as tracheal secretions contaminate the wound continuously (28). Proper daily wound care is imperative to avoid this complication (4). In patients with prolonged tracheostomy, the pressure of tube flange or swivel adapter edge against sternum can increase the risk. Stomal cellulitis should be treated with empiric antibiotics targeted towards skin and respiratory flora, and subsequently tailored to wound culture results if purulent drainage is present (Figure 3). In necrotizing wound infections, conversion to orotracheal intubation is recommended (4). Frequent routine tracheostomy changes every 30-60 days can prevent biofilm formation and subsequently minimize risk of infections $(4,64)$.

\section{Prevention with checklists}

In light of the potentially serious outcomes associated with complications of PDT, the emphasis should be placed on risk-reduction strategies to minimize morbidity and mortality. We present a comprehensive checklist to serve as a reference for clinicians involved in PDT placements (Table 1). Future studies must focus on prospective and randomized controlled trials to identify novel techniques for PDT that confer safer outcomes.

\section{Complications of PEG}

Since its introduction by Gauderer et al. in the 1980s (65), percutaneous endoscopic gastrostomy (PEG), has rapidly become the most common method of feeding 
Table 1 Suggested checklist for bedside percutaneous tracheostomy placement

\begin{tabular}{|c|c|c|}
\hline Pre-procedural & Procedural & Post-procedural \\
\hline Correct coagulopathy & $\begin{array}{l}\text { Bronchoscopic guidance during entire } \\
\text { procedure }\end{array}$ & $\begin{array}{l}\text { Avoid cuff overinflation and excessive } \\
\text { cuff pressures; daily recording of } \\
\text { pressures; target pressures }<25 \mathrm{mmHg}\end{array}$ \\
\hline Physical exam and bedside ultrasound of neck & $\begin{array}{l}\text { Performance by or supervision by } \\
\text { experienced operator }\end{array}$ & $\begin{array}{l}\text { Avoid early trachesotomy change; first } \\
\text { change after } 7-14 \text { days; use of guiding } \\
\text { catheter; consider delaying first trach } \\
\text { change to } 30 \text { days }\end{array}$ \\
\hline $\begin{array}{l}\text { Ensure vasopressors and fluids available in } \\
\text { room }\end{array}$ & $\begin{array}{l}\text { Airway management by physicians } \\
\text { experienced in difficult airway } \\
\text { management }\end{array}$ & Daily tracheostomy site asessement \\
\hline Ensure emergency airway kit available in room & $\begin{array}{l}\text { Avoid low tracheostomy puncture site; } \\
\text { aim for } 1^{\text {st }}-2^{\text {nd }} \text { or } 2^{\text {nd }}-3^{\text {rd }} \text { tracheal ring }\end{array}$ & Routine change every $30-60$ days \\
\hline Preoxygenation with $\mathrm{FiO}_{2}$ at $100 \%$ & $\begin{array}{l}\text { Avoid guidewire kinking: use } \\
\text { percutaneous tracheostomy kit with ridge; } \\
\text { stabilize guiding catheter and dilator }\end{array}$ & \\
\hline $\begin{array}{l}\text { Ventilator settings with low pressure, low tidal } \\
\text { volumes, high respiratory rates }\end{array}$ & $\begin{array}{l}\text { Use of extra-long proximal XLT cannulas in } \\
\text { obese necks }\end{array}$ & \\
\hline
\end{tabular}

and nutritional support in patients with a functional gastrointestinal system who require mid to long term enteral feeding (66). Compared to nasoenteral feeding, it results in fewer complications such as aspiration pneumonia, reflux, or esophageal ulceration, and provides improved comfort and feeding efficiency for the patient $(67,68)$. An estimated 200,000-250,000 procedures are performed annually in the USA (69). PEG outperforms surgical and radiological gastrostomy in terms of safety profile, complication rates, and mortality $(68,70)$. Although generally considered a safe and minimally invasive procedure, it is associated with both minor and major complications, with reported 30-day mortality as high as $24 \%$ in some studies (71). Here we describe the major and some minor complications, including strategies for their prevention and management.

Published rates of complications after PEG are variable and range between $13-70 \%$. Risk factors for complications include underlying malignancy $(72,73)$, older age $(72,74,75)$, history of aspiration pneumonia (75), diabetes (72), prior abdominal surgeries (76), and the presence of neurological diseases $(77,78)$.

\section{Major complications}

\section{Bleeding}

Bleeding occurs in up to $2.5 \%$ of PEG placements $(79,80)$. It can occur from the gastrointestinal tract due to gastric ulcerations $(80,81)$, the abdominal wall, or from injury to large vessels such as the gastric artery and splenic or mesenteric veins $(82,83)$. Intra- or retroperitoneal bleeding (84) and rectus sheath hematoma (85) have also been reported.

Bleeding is most commonly an early complication 
and manifests as oozing around the gastrostomy site, hematemesis, melena, or unexplained anemia (86). Minor bleeding can be due to granulation tissue formation that occurs as a response to foreign body insertion, friction, and excess moisture due to fluid leakage $(87,88)$. It is usually self-limited or resolves with application of manual pressure over the abdominal wound $(66,86)$. If persistent bleeding occurs, however, tightening the external bolster to compress the gastrostomy tract can help tamponade the bleed (86). Tightening the bolster for more than 48 hours should be avoided, as this can lead to pressure injuries and necrosis. Cauterization of the granulation tissue with silver nitrate or APC can also be effective $(76,86,88)$. Rarely, intraluminal or intraperitoneal bleeding may require endoscopic or surgical exploration $(66,86)$. Transarterial embolization of injured branches of larger vessels such as superior mesenteric artery to achieve hemostasis has also been described (82).

Not surprisingly, coagulopathy, thrombocytopenia, and the use of anticoagulation increases bleeding risk $(89,90)$. Studies have shown no increased risk in patients taking clopidogrel or aspirin (91). There is scarse published data regarding the safety of performing PEG on newer agents such as prasugrel, ticagrelor, or novel direct oral anticoagulants (DOAC) (90). In one study, the use of selective serotonin receptor inhibitors (SSRI) placed patients at a higher risk for bleeding complications (91).

\section{Injury to internal organs}

Intra-abdominal organs such as the colon $(92,93)$, small bowel (94), liver $(95,96)$, and spleen (84) are all potential sites of injury during PEG placement. Patients with prior abdominal surgeries and post-op adhesions are at a particularly high risk for this complication (76), as are older patients due to an increased laxity of the colonic mesentery (92). Viscus organ injury can manifest as bleeding or peritonitis in the early stages, and chronic colo-cutaneous or enterocutaneous fistula later on (86). If viscus organ perforation is suspected, computerized tomography (CT) scanning with water soluble contrast can be performed, looking for leakage of contrast into peritoneal cavity for confirmation. While asymptomatic pneumoperitonitis is often seen on post-operative imaging, any persistence of air over 72 hours, no matter how small, with development of new symptoms should prompt immediate evaluation for organ damage (86).

Conservative management with close surveillance is a reasonable approach in hemodynamically stable patients with no signs of sepsis. Surgical exploration is indicated in all decompensating patients with signs of active peritonitis or sepsis.

Proper technique with transillumination and careful palpation of stomach can help prevent such complications. A "safe-tract technique" proposed by Foutch et al. can further help avoid organ injury. In this method, the needle of the syringe with fluid in the barrel is advanced with traction on the plunger until air bubbles are seen in the chamber. Air or fluid reaching the syringe before the needle is visualized by the gastroscope inside the stomach indicates a problem with technique, warranting a careful revision of procedural steps taken (97).

\section{Necrotizing fasciitis}

Necrotizing fasciitis, a rare but potentially fatal complication of PEG placement, is a true surgical emergency and carries a mortality rate of $50-80 \%$ (98). It is characterized by a severe bacterial infection of the surrounding soft tissue with acute and rapid progression around the PEG site and along the fascial planes, leading to abdominal fascial necrosis (99-101). Group A streptococci, anaerobes, staphylococcus and Enterobacteriaceae are the most notable causative agents, although polymicrobial infections are also common (102). Underlying diabetes, malignancy, and immunosuppression can all predispose patients to this complication (101). Additionally, traction and pressure from external bolsters positioned too tightly against the abdominal wall are major contributing factors (101). Treatment consists of empiric intravenous broad-spectrum antibiotics and immediate wide surgical debridement $(66,86)$.

\section{Aspiration pneumonia}

It is a common misconception that PEG placement prevents aspiration. In numerous studies, PEG placement for dysphagia after a stroke has failed to show a reduction in aspiration pneumonia $(103,104)$. In one study of patients with a history of stroke aspiration pneumonia was the most common complication, occurring in $18 \%$ of patients (103). Aspiration can occur intra-procedurally as a consequence of moderate sedation in supine position, or as a late complication after initiation of tube feeds (86). Postpyloric or jejunal extension introduced transgastrically via gastrostomy tube may decrease aspiration, but is technically challenging with high failure rates and increased tube dysfunction and dislocation (105).

\section{Buried bumper syndrome}

Buried bumper syndrome occurs from excessive 

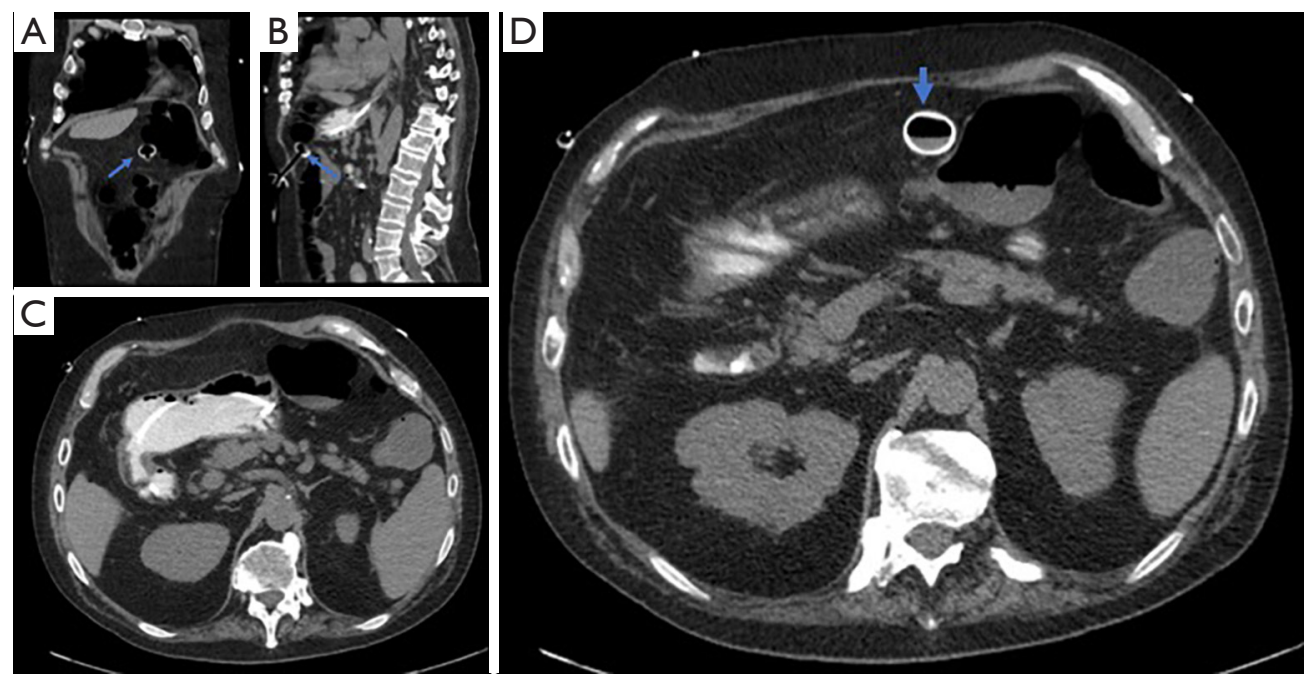

Figure 4 Buried Bumper Syndrome on computed tomography (CT). Blue arrow showing bumper position outside of the stomach wall and in the mesentary on (A) coronal view, (B) sagittal view, and (C,D) cross-sectional views.

compression of tissue due to tight apposition of the external bolster against the abdominal wall $(106,107)$. This causes the internal bolster to migrate anywhere from the gastric wall outwards towards the outer abdominal wall and even subcutaneous tissue and skin (Figure 4). This can occur as early as 3 weeks after PEG placement, and can present as pain, loss of tube patency, and leakage around the tube (108). The bolster can at times be palpated subcutaneously on exam or seen buried in the mucosa on endoscopy. Left untreated, this complication can ultimately lead to bleeding, perforation of the stomach, peritonitis, abscess development, or even death $(66,106)$.

Treatment depends on the type of PEG tube placed. If a soft or balloon internal fixation is used, the buried system can be extracted simply by pulling (108). In some cases, the buried tube can also be extracted with the simultaneous insertion of a new tube $(109,110)$. A wire introduced into the stomach through the existing system is then grasped endoscopically and pulled out of the mouth. The new tube is then attached to the wire and placed into the stomach by pulling the wire. As the new tube is pulled through the original gastrostomy tract, the old buried system is pushed out $(109,110)$.

In another method called the "push-pull T technique", a snare is passed via an endoscope through the gastric stoma opening and out of the pre-shortened tube. The snare is then used to grasp a short piece of the cut tubing and pull it internally toward the end of the gastrostomy tube. The endoscope and snare are retracted as one unit, with simultaneous pushing of the tube from the outside via surgical clamps, leading to extraction of the gastrostomy tube into the stomach (111).

Other endoscopic techniques, such as dissection with a needle knife $(112)$, incision with a papillotome $(113,114)$ or destruction with argon plasma coagulation (115), have been reported. A novel safe technique using a HookKnife (Olympus Endotherapy) has recently been described for retrieval of buried PEG bumpers in which a rotating L-shaped cutting wire is used. This wire is designed for hooking tissue and pulling it away from the gastric wall towards the lumen, and is commonly used for colonic polypectomies (116). In rare circumstances, surgical extraction via laparotomy is performed if the bumper is buried in an abscess between gastric and abdominal wall (117).

It is often recommended to position the external bolster (or fixation device) around 1-2 cm from the abdominal wall (66). Gauze pads should be placed over, and not underneath the bolster to prevent even more pressure against the abdominal wall. The recommended distance, however, is still a matter of controversy. While some advocate for this looser positioning to prevent necrosis and buried bumper syndrome $(101,107)$, other authors recommend a tighter apposition for at least the first 4 days to avoid leakage (106). During daily care, pushing the tube forward and performing 180-360 degree rotation at least once weekly can prevent this complication (66). 


\section{Tumor seeding}

There is a theoretical risk of tumor seeding in patients with head and neck or esophageal cancer (118-120). It is thought to occur as the gastrostomy tube comes in contact with the primary tumor during placement, particularly with "push" and "pull" methods of placement. In a study of 40 patients with oropharyngeal cancer who underwent PEG placement using the "pull" technique, $22.5 \%$ had malignant cells present in tubing and at the incision immediately after procedure based on brushings of these sites. Another 9\% had document malignant cells at these locations 3 months post-PEG placement (118). Due to the increased incidence of seeding with older age and higher tumor burden (118), the use of direct access PEG in these instances is recommended (121).

\section{Minor complications}

\section{Wound infection}

Tube site infection is the most common complication of PEG placement and occurs in $5-25 \%$ of cases (66). Although erythema is normally seen to a certain degree due to friction and manipulation of the tube, the presence of tenderness, purulent discharge, or signs of sepsis indicate an evolving wound infection. Minor infections can be treated with topical antiseptics with frequent dressing change, however most infections ultimately require antibiotics effective for soft-tissue infections such as cephalosporins or fluoroquinolones $(66,122)$. An increasing number of infections due to methicillin-resistant staphylococcus aureus (MRSA) and fungal infections have also been seen (86). Wound cultures from purulent discharge can help narrow antibiotics according to susceptibilities. Tube removal is generally not required when the infection is well-controlled with antibiotics alone (86).

Current guidelines recommend a single dose of an intravenous cephalosporin one hour prior to PEG insertion $(123,124)$. A systematic review of 10 randomized controlled trials involving 1,100 patients showed a significant relative risk reduction in the incidence of peristomal infections of $64 \%$ with prophylactic antibiotics (125). Other studies exploring trimethoprim-sulfamethoxazole administered immediately through the newly inserted catheter showed similar outcomes for wound infection reduction as pre-operative cefuroxime use $(126,127)$. Lastly, a retrospective study of 331 patients showed that application of topical antibacterial polyhexamethylene biguanide gauze immediately following PEG insertion for
3 days was comparable to parenteral antibiotics in preventing peristomal wound infection after PEG placement (128).

\section{Tube dislodgement}

Tube dislodgment is another common complication, with a reported incidence of $4-13 \%$ (86). The gastrostomy tube can either be dislodged interiorly into the stomach or externally due to internal balloon deflation, external bumper removal, or accidental pulling. The abdominal wall tract is considered mature one month after PEG insertion. If dislodgement occurs prior to this time frame, the stomach and abdominal wall may have already separated, and therefore blind placement is not recommended as it can lead to placement into peritoneal cavity (129). New tube placement near or through the dislodged tube side should be done with endoscopic confirmation. Older gastrostomy tubes with mature tracts should be replaced as soon as possible and can be done blindly at the bedside $(129,130)$.

\section{Peristomal leakage}

Peristomal leakage usually occurs as an early complication within a few days of PEG placement, although some cases have been reported after tube maturation (66). Patients with a history of prior gastric surgeries or with underlying medical conditions that lead to altered wound healing such as diabetes, immunodeficiency, or severe malnutrition are predisposed to peristomal leakage $(72,131)$. Care must be taken to rule out potential causes of peristomal leakage such as a tight closure with the external bolster, infection, buried bumper, enlarged gastric fistula, slowed gastric emptying, excessive residual feeds, or ulceration $(66,86)$.

Treatment is largely targeted towards prevention and management of any of the potential underlying conditions mentioned above. Insertion of a larger bore gastrostomy tube is not recommended as it only serves to enlarge the existing leaking stoma and cause further skin breakdown (76). In an older gastrostomy tube with a mature tract, the tube can be removed for a few days to allow for partial closure. A wire is placed through the stoma to secure the tract and to guide placement of a new tube at the same site when ready (130). Alternatively, the tube can be removed longer-term to allow for complete tract closure before placement of a new PEG tube in a different location on the abdominal wall (132).

\section{Gastric outlet obstruction}

Occasionally, the external bolster can pull away from the abdominal wall, allowing migration of the gatrostomy tube 
Table 2 Suggested checklist for bedside percutaneous gastrostomy placement

\begin{tabular}{lll}
\hline Pre-procedural & Procedural & Post-procedural \\
\hline $\begin{array}{l}\text { Strict consideration of contraindications: } \\
\text { esophageal obstruction, total gastrectomy, } \\
\text { extreme obesity, massive ascites, portal } \\
\text { hypertension, peritoneal dialysis, active } \\
\text { gastric pathology, hemodynamic instability, } \\
\text { coagulopathy }\end{array}$ & $\begin{array}{l}\text { Performance by or supervision by } \\
\text { experienced operator. Use the "safe-tract } \\
\text { technique". Confirm PEG site by } \\
\text { gastroscopic transillumination and manual } \\
\text { palpation }\end{array}$ & Bed rest for at least 6 hours after placement \\
Administer prophylactic antibiotic & $\begin{array}{l}\text { Consider administration of } \\
\text { sulfamethoxazole-trimethoprim through } \\
\text { the PEG tube if pre-procedure antibiotic } \\
\text { was not given }\end{array}$ & $\begin{array}{l}\text { Clean the peristomal area, PEG tube and } \\
\text { warm water; and dry after use. Keep the cap } \\
\text { closed when not in use }\end{array}$ \\
$\begin{array}{l}\text { Shave abdominal skin if needed, disinfect } \\
\text { with a colorless disinfectant, remove }\end{array}$ & $\begin{array}{l}\text { Avoid tight apposition of the external } \\
\text { bolster against the abdominal wall }\end{array}$ & $\begin{array}{l}\text { Rotate tube clockwise and counterclockwise } \\
\text { daily ensuring the external bolster is not } \\
\text { dentures, suction oral secretions }\end{array}$ \\
$\begin{array}{l}\text { Correct coagulopathy } \\
\text { After placement, repeat endoscopy to }\end{array}$ & \\
& $\begin{array}{l}\text { confirm optimal placement, rule out } \\
\text { immediate complications, and set the } \\
\text { internal bumper under direct vision }\end{array}$ & \\
\hline
\end{tabular}

into the stomach and duodenum, causing obstruction of pyloric area (133-135). This leads to crampy abdominal pain, nausea, and vomiting. Endoscopy is used to confirm the migration and subsequently retract the tube back to its original positioning. Secure positioning of the external bolster is key to preventing this complication (76).

\section{Conclusion}

Although complications from PEG placement are rare, they can be devastating with fatal outcomes. As many patients undergoing a PEG tube placement have underlying neurological disease, altered mental status, or critical illness, their ability to communicate symptoms is somewhat limited, rendering early diagnosis of complications somewhat challenging. We reinforce the pivotal role prevention plays in the success of PEG placement and lowering complication rates. We also present a comprehensive checklist to serve as a reference for clinicians involved in PEG placements (Table 2).

\section{Acknowledgments}

Funding: None.

\section{Footnote}

Provenance and Peer Review: This article was commissioned by the Guest Editors (Jonathan S. Kurman, Ashutosh Sachdeva and Rahul Nanchal) for the series "Interventional Pulmonology in the Intensive Care Unit Environment" published in fournal of Thoracic Disease. The article has undergone external peer review.

Conflicts of Interest: Both authors have completed the ICMJE uniform disclosure form (available at http://dx.doi. org/10.21037/jtd-19-3716). The series "Interventional Pulmonology in the Intensive Care Unit Environment" was commissioned by the editorial office without any funding sponsorship. The authors have no other conflicts of interest to declare.

Ethical Statement: The authors are accountable for all aspects of the work in ensuring that questions related to the accuracy or integrity of any part of the work are appropriately investigated and resolved.

Open Access Statement: This is an Open Access article distributed in accordance with the Creative Commons Attribution-NonCommercial-NoDerivs 4.0 International License (CC BY-NC-ND 4.0), which permits the noncommercial replication and distribution of the article with the strict proviso that no changes or edits are made and the original work is properly cited (including links to both the formal publication through the relevant DOI and the license). 
See: https://creativecommons.org/licenses/by-nc-nd/4.0/.

\section{References}

1. Trottier SJ, Hazard PB, Sakabu SA, et al. Posterior tracheal wall perforation during percutaneous dilational tracheostomy: an investigation into its mechanism and prevention. Chest 1999;115:1383-9.

2. Ciaglia P, Firsching R, Syniec C. Elective percutaneous dilatational tracheostomy. A new simple bedside procedure; preliminary report. Chest 1985;87:715-9.

3. Yu M. Tracheostomy patients on the ward: multiple benefits from a multidisciplinary team? Crit Care 2010;14:109.

4. Lerner AD, Yarmus L. Percutaneous Dilational Tracheostomy. Clin Chest Med 2018;39:211-22.

5. Das P, Zhu H, Shah RK, et al. Tracheotomy-related catastrophic events: results of a national survey. Laryngoscope 2012;122:30-7.

6. Simon M, Metschke M, Braune SA, et al. Death after percutaneous dilatational tracheostomy: a systematic review and analysis of risk factors. Crit Care 2013;17:R258.

7. Epstein SK. Late complications of tracheostomy. Respir Care 2005;50:542-9.

8. De Leyn P, Bedert L, Delcroix M, et al. Tracheotomy: clinical review and guidelines is . Eur J Cardiothorac Surg 2007;32:412-21.

9. Fernandez-Bussy S, Mahajan B, Folch E, et al. Tracheostomy Tube Placement: Early and Late Complications. J Bronchology Interv Pulmonol 2015;22:357-64.

10. Klemm E, Nowak AK. Tracheotomy-Related Deaths. Dtsch Arztebl Int 2017;114:273-9.

11. Goldenberg D, Ari EG, Golz A, et al. Tracheotomy complications: a retrospective study of 1130 cases. Otolaryngol Head Neck Surg 2000;123:495-500.

12. Fikkers BG, van Veen JA, Kooloos JG, et al. Emphysema and pneumothorax after percutaneous tracheostomy: case reports and an anatomic study. Chest 2004;125:1805-14.

13. Tomsic JP, Connolly MC, Joe VC, et al. Evaluation of bronchoscopic-assisted percutaneous tracheostomy. Am Surg 2006;72:970-2.

14. Cabrini L, Greco M, Pasin L, et al. Preventing deaths related to percutaneous tracheostomy: safety is never too much! Crit Care 2014;18:406.

15. Sheu CC, Tsai JR, Cheng MH, et al. Safety of performing percutaneous dilational tracheostomy in patients with preexisting barotrauma. Kaohsiung J Med
Sci 2006;22:570-4.

16. Byhahn C, Wilke HJ, Halbig S, et al. Percutaneous tracheostomy: ciaglia blue rhino versus the basic ciaglia technique of percutaneous dilational tracheostomy. Anesth Analg 2000;91:882-6.

17. Miñambres E, Buron J, Ballesteros MA, et al. Tracheal rupture after endotracheal intubation: a literature systematic review. Eur J Cardiothorac Surg 2009;35:1056-62.

18. Cardillo G, Carbone L, Carleo F, et al. Tracheal lacerations after endotracheal intubation: a proposed morphological classification to guide non-surgical treatment. Eur J Cardiothorac Surg 2010;37:581-7.

19. Ovári A, Just T, Dommerich S, et al. Conservative management of post-intubation tracheal tears-report of three cases. J Thorac Dis 2014;6:E85-91.

20. Carbognani P, Bobbio A, Cattelani L, et al. Management of postintubation membranous tracheal rupture. Ann Thorac Surg 2004;77:406-9.

21. Sippel M, Putensen C, Hirner A, et al. Tracheal rupture after endotracheal intubation: experience with management in 13 cases. Thorac Cardiovasc Surg 2006;54:51-6.

22. Gabor S, Renner H, Pinter H, et al. Indications for surgery in tracheobronchial ruptures. Eur J Cardiothorac Surg 2001;20:399-404.

23. Georges H, Leroy O, Guery B, et al. Predisposing factors for nosocomial pneumonia in patients receiving mechanical ventilation and requiring tracheotomy. Chest 2000;118:767-74.

24. Conti M, Pougeoise M, Wurtz A, et al. Management of postintubation tracheobronchial ruptures. Chest 2006;130:412-8.

25. Yopp AC, Eckstein JG, Savel RH, et al. Tracheal stenting of iatrogenic tracheal injury: a novel management approach. Ann Thorac Surg 2007;83:1897-9.

26. Creagh-Brown B, Sheth A, Crerar-Gilbert A, et al. A novel approach to the management of acute tracheal tear. J Laryngol Otol 2008;122:1392-3.

27. Madden BP, Sheth A, Ho TB, et al. Novel approach to management of a posterior tracheal tear complicating percutaneous tracheostomy. Br J Anaesth 2004;92:437-9.

28. Rashid AO, Islam S. Percutaneous tracheostomy: a comprehensive review. J Thorac Dis 2017;9:S1128-38.

29. Ernst A, Garland R, Zibrak J. Percutaneous Tracheostomy. Journal of Bronchology \& Interventional Pulmonology 1998;5:247-50.

30. Feller-Kopman D. Acute complications of artificial airways. Clin Chest Med 2003;24:445-55. 
31. Chambers D, Cloyes R, Adam A, et al. Percutaneous Tracheostomy in Severe Obesity: Experience at a Tertiary Care Center. Chest 2013;144:66A.

32. Jaber S, Jung B, Corne $\mathrm{P}$, et al. An intervention to decrease complications related to endotracheal intubation in the intensive care unit: a prospective, multiple-center study. Intensive Care Med 2010;36:248-55.

33. Zias N, Chroneou A, Tabba MK, et al. Post tracheostomy and post intubation tracheal stenosis: report of 31 cases and review of the literature. BMC Pulm Med 2008;8:18.

34. Law RC, Carney AS, Manara AR. Long-term outcome after percutaneous dilational tracheostomy. Endoscopic and spirometry findings. Anaesthesia 1997;52:51-6.

35. Barros Casas D, Fernández-Bussy S, Folch E, et al. Non-Malignant Central Airway Obstruction. Arch Bronconeumol 2014;50:345-54.

36. Ernst A, Herth FJF, editors. Principles and practice of interventional pulmonology. Springer-Verlag New York; 2016.

37. Murgu SD, Egressy K, Laxmanan B, et al. Central Airway Obstruction: Benign Strictures, Tracheobronchomalacia, and Malignancy-related Obstruction. Chest 2016;150:426-41.

38. Grillo HC, Mathisen DJ. Surgical management of tracheal strictures. Surg Clin North Am 1988;68:511-24.

39. Dalar L, Sokucu SN, Unver N, et al. Initial bronchoscopic treatment of tracheal schwannoma: a rarely seen tumour. West Indian Med J 2014;63:209-11.

40. Mehta AC, Lee FY, Cordasco EM, et al. Concentric tracheal and subglottic stenosis. Management using the Nd-YAG laser for mucosal sparing followed by gentle dilatation. Chest 1993;104:673-7.

41. Brichet A, Verkindre C, Dupont J, et al. Multidisciplinary approach to management of postintubation tracheal stenoses. Eur Respir J 1999;13:888-93.

42. Bhora FY, Ayub A, Forleiter CM, et al. Treatment of Benign Tracheal Stenosis Using Endoluminal Spray Cryotherapy. JAMA Otolaryngol Head Neck Surg 2016;142:1082-7.

43. Fernando HC, Dekeratry D, Downie G, et al. Feasibility of spray cryotherapy and balloon dilation for nonmalignant strictures of the airway. Eur J Cardiothorac Surg 2011;40:1177-80.

44. Smith ME, Elstad M. Mitomycin C and the endoscopic treatment of laryngotracheal stenosis: are two applications better than one? Laryngoscope 2009;119:272-83.

45. Noppen M, Schlesser M, Meysman M, et al. Bronchoscopic balloon dilatation in the combined management of postintubation stenosis of the trachea in adults. Chest 1997;112:1136-40.

46. Tsakiridis K, Darwiche K, Visouli AN, et al. Management of complex benign post-tracheostomy tracheal stenosis with bronchoscopic insertion of silicon tracheal stents, in patients with failed or contraindicated surgical reconstruction of trachea. J Thorac Dis 2012;4 Suppl 1:32-40.

47. Lim SY, Kim H, Jeon K, et al. Prognostic factors for endotracheal silicone stenting in the management of inoperable post-intubation tracheal stenosis. Yonsei Med J 2012;53:565-70.

48. Puma F, Ragusa M, Avenia N, et al. The role of silicone stents in the treatment of cicatricial tracheal stenoses. J Thorac Cardiovasc Surg 2000;120:1064-9.

49. Saad SA, Falla A. Management of intractable and extensive tracheal stenosis by implantation of cartilage graft. J Pediatr Surg 1983;18:472-4.

50. Wurtz A, Porte H, Conti M, et al. Tracheal replacement with aortic allografts. N Engl J Med 2006;355:1938-40.

51. Macchiarini P, Jungebluth P, Go T, et al. Clinical transplantation of a tissue-engineered airway. Lancet 2008;372:2023-30.

52. Feist JH, Johnson TH, Wilson RJ. Acquired tracheomalacia: etiology and differential diagnosis. Chest 1975;68:340-5.

53. Sue RD, Susanto I. Long-term complications of artificial airways. Clin Chest Med 2003;24:457-71.

54. Wood DE, Mathisen DJ. Late complications of tracheotomy. Clin Chest Med 1991;12:597-609.

55. Seegobin RD, van Hasselt GL. Endotracheal cuff pressure and tracheal mucosal blood flow: endoscopic study of effects of four large volume cuffs. Br Med J (Clin Res Ed) 1984;288:965-8.

56. Sultan P, Carvalho B, Rose BO, et al. Endotracheal tube cuff pressure monitoring: a review of the evidence. J Perioper Pract 2011;21:379-86.

57. Cooper JD. Trachea-innominate artery fistula: successful management of 3 consecutive patients. Ann Thorac Surg 1977;24:439-47.

58. Cipriano A, Mao ML, Hon HH, et al. An overview of complications associated with open and percutaneous tracheostomy procedures. Int J Crit Illn Inj Sci 2015;5:179-88.

59. Dartevelle P, Macchiarini P. Management of acquired tracheoesophageal fistula. Chest Surg Clin N Am 1996;6:819-36.

60. Chua AP, Dalal B, Mehta AC. Tracheostomy Tube- 
induced Tracheoesophageal Fistula. J Bronchology Interv Pulmonol 2009;16:191-2.

61. Macchiarini P, Verhoye JP, Chapelier A, et al. Evaluation and outcome of different surgical techniques for postintubation tracheoesophageal fistulas. J Thorac Cardiovasc Surg 2000;119:268-76.

62. Mathisen DJ, Grillo HC, Wain JC, et al. Management of acquired nonmalignant tracheoesophageal fistula. Ann Thorac Surg 1991;52:759-65.

63. Marquette $\mathrm{CH}$, Bocquillon $\mathrm{N}$, Roumilhac $\mathrm{D}$, et al. Conservative treatment of tracheal rupture. J Thorac Cardiovasc Surg 1999;117:399-401.

64. White AC, Kher S, O'Connor HH. When to change a tracheostomy tube. Respir Care 2010;55:1069-75.

65. Gauderer MW, Ponsky JL, Izant RJ, Jr. Gastrostomy without laparotomy: a percutaneous endoscopic technique. J Pediatr Surg 1980;15:872-5.

66. Rahnemai-Azar AA, Rahnemaiazar AA, Naghshizadian R, et al. Percutaneous endoscopic gastrostomy: indications, technique, complications and management. World J Gastroenterol 2014;20:7739-51.

67. Baeten C, Hoefnagels J. Feeding via nasogastric tube or percutaneous endoscopic gastrostomy. A comparison. Scand J Gastroenterol Suppl 1992;194:95-8.

68. Park RH, Allison MC, Lang J, et al. Randomised comparison of percutaneous endoscopic gastrostomy and nasogastric tube feeding in patients with persisting neurological dysphagia. BMJ 1992;304:1406-9.

69. Gauderer M. Twenty years of percutaneous endoscopic gastrostomy: origin and evolution of a concept and its expanded applications. Gastrointest Endosc 1999;50:879-83.

70. Mekhail TM, Adelstein DJ, Rybicki LA, et al. Enteral nutrition during the treatment of head and neck carcinoma: is a percutaneous endoscopic gastrostomy tube preferable to a nasogastric tube? Cancer 2001;91:1785-90.

71. Grant MD, Rudberg MA, Brody JA. Gastrostomy placement and mortality among hospitalized Medicare beneficiaries. JAMA 1998;279:1973-6.

72. Pih GY, Na HK, Ahn JY, et al. Risk factors for complications and mortality of percutaneous endoscopic gastrostomy insertion. BMC Gastroenterol 2018;18:101.

73. Grant DG, Bradley PT, Pothier DD, et al. Complications following gastrostomy tube insertion in patients with head and neck cancer: a prospective multi-institution study, systematic review and meta-analysis. Clin Otolaryngol 2009;34:103-12.

74. Arora G, Rockey D, Gupta S. High In-hospital mortality after percutaneous endoscopic gastrostomy: results of a nationwide population-based study. Clin Gastroenterol Hepatol 2013;11:1437-44.e3.

75. Light VL, Slezak FA, Porter JA, et al. Predictive factors for early mortality after percutaneous endoscopic gastrostomy. Gastrointest Endosc 1995;42:330-5.

76. Schrag SP, Sharma R, Jaik NP, et al. Complications related to percutaneous endoscopic gastrostomy (PEG) tubes. A comprehensive clinical review. J Gastrointestin Liver Dis 2007;16:407-18.

77. Blomberg J, Lagergren J, Martin L, et al. Complications after percutaneous endoscopic gastrostomy in a prospective study. Scand J Gastroenterol 2012;47:737-42.

78. Lee SP, Lee KN, Lee OY, et al. Risk factors for complications of percutaneous endoscopic gastrostomy. Dig Dis Sci 2014;59:117-25.

79. Larson DE, Burton DD, Schroeder KW, et al. Percutaneous endoscopic gastrostomy. Indications, success, complications, and mortality in 314 consecutive patients. Gastroenterology 1987;93:48-52.

80. Schapiro GD, Edmundowicz SA. Complications of percutaneous endoscopic gastrostomy. Gastrointest Endosc Clin N Am 1996;6:409-22.

81. Cappell MS, Abdullah M. Management of gastrointestinal bleeding induced by gastrointestinal endoscopy. Gastroenterol Clin North Am 2000;29:125-67, vi-vii.

82. Lee SH, Moon HS, Park JH, et al. Percutaneous Endoscopic Gastrostomy Tube Insertion-induced Superior Mesenteric Artery Injury Treated with Angiography. Korean J Gastroenterol 2018;72:308-12.

83. Schurink CA, Tuynman H, Scholten P, et al. Percutaneous endoscopic gastrostomy: complications and suggestions to avoid them. Eur J Gastroenterol Hepatol 2001;13:819-23.

84. Lau G, Lai SH. Fatal retroperitoneal haemorrhage: an unusual complication of percutaneous endoscopic gastrostomy. Forensic Sci Int 2001;116:69-75.

85. Ubogu EE, Zaidat OO. Rectus sheath hematoma complicating percutaneous endoscopic gastrostomy. Surg Laparosc Endosc Percutan Tech 2002;12:430-2.

86. Hucl T, Spicak J. Complications of percutaneous endoscopic gastrostomy. Best Pract Res Clin Gastroenterol 2016;30:769-81.

87. Borkowski S. G tube care: managing hypergranulation tissue. Nursing 2005;35:24.

88. Warriner L, Spruce P. Managing overgranulation tissue around gastrostomy sites. Br J Nurs 2012;21:S14-6, S8, S20 passim.

89. Itkin M, DeLegge MH, Fang JC, et al. Multidisciplinary practical guidelines for gastrointestinal access for 
enteral nutrition and decompression from the Society of Interventional Radiology and American Gastroenterological Association (AGA) Institute, with endorsement by Canadian Interventional Radiological Association (CIRA) and Cardiovascular and Interventional Radiological Society of Europe (CIRSE). J Vasc Interv Radiol 2011;22:1089-106.

90. Veitch AM, Vanbiervliet G, Gershlick AH, et al. Endoscopy in patients on antiplatelet or anticoagulant therapy, including direct oral anticoagulants: British Society of Gastroenterology (BSG) and European Society of Gastrointestinal Endoscopy (ESGE) guidelines. Endoscopy 2016;48:385-402.

91. Richter JA, Patrie JT, Richter RP, et al. Bleeding after percutaneous endoscopic gastrostomy is linked to serotonin reuptake inhibitors, not aspirin or clopidogrel. Gastrointest Endosc 2011;74:22-34.e1.

92. Ahmad J, Thomson S, McFall B, et al. Colonic injury following percutaneous endoscopic-guided gastrostomy insertion. BMJ Case Rep 2010;2010:bcr0520102976.

93. Guloglu R, Taviloglu K, Alimoglu O. Colon injury following percutaneous endoscopic gastrostomy tube insertion. J Laparoendosc Adv Surg Tech A 2003;13:69-72.

94. Karhadkar AS, Schwartz HJ, Dutta SK. Jejunocutaneous fistula manifesting as chronic diarrhea after PEG tube replacement. J Clin Gastroenterol 2006;40:560-1.

95. Wiggins TF, Kaplan R, DeLegge MH. Acute hemorrhage following transhepatic PEG tube placement. Dig Dis Sci 2007;52:167-9.

96. Chaer RA, Rekkas D, Trevino J, et al. Intrahepatic placement of a PEG tube. Gastrointest Endosc 2003;57:763-5.

97. Foutch PG, Talbert GA, Waring JP, et al. Percutaneous endoscopic gastrostomy in patients with prior abdominal surgery: virtues of the safe tract. Am J Gastroenterol 1988;83:147-50.

98. Burkitt P, Carter LM, Smith AB, et al. Outcomes of percutaneous endoscopic gastrostomy and radiologically inserted gastrostomy in patients with head and neck cancer: a systematic review. Br J Oral Maxillofac Surg 2011;49:516-20.

99. Evans DA, Bhandarkar DS, Taylor TV. Necrotising fasciitis--a rare complication of percutaneous endoscopic gastrostomy. Endoscopy 1995;27:627.

100. MacLean AA, Miller G, Bamboat ZM, et al. Abdominal wall necrotizing fasciitis from dislodged percutaneous endoscopic gastrostomy tubes: a case series. Am Surg 2004;70:827-31.
101. Chung RS, Schertzer M. Pathogenesis of complications of percutaneous endoscopic gastrostomy. A lesson in surgical principles. Am Surg 1990;56:134-7.

102. Giuliano A, Lewis F, Jr., Hadley K, et al. Bacteriology of necrotizing fasciitis. Am J Surg 1977;134:52-7.

103.James A, Kapur K, Hawthorne AB. Long-term outcome of percutaneous endoscopic gastrostomy feeding in patients with dysphagic stroke. Age Ageing 1998;27:671-6.

104. Finucane TE, Bynum JP. Use of tube feeding to prevent aspiration pneumonia. Lancet 1996;348:1421-4.

105.DiSario JA. Endoscopic approaches to enteral nutritional support. Best Pract Res Clin Gastroenterol 2006;20:605-30.

106.McClave SA, Jafri NS. Spectrum of morbidity related to bolster placement at time of percutaneous endoscopic gastrostomy: buried bumper syndrome to leakage and peritonitis. Gastrointest Endosc Clin N Am 2007;17:731-46.

107.DeLegge M, DeLegge R, Brady C. External bolster placement after percutaneous endoscopic gastrostomy tube insertion: is looser better? JPEN J Parenter Enteral Nutr 2006;30:16-20.

108. Cyrany J, Rejchrt S, Kopacova M, et al. Buried bumper syndrome: A complication of percutaneous endoscopic gastrostomy. World J Gastroenterol 2016;22:618-27.

109. Venu RP, Brown RD, Pastika BJ, et al. The buried bumper syndrome: a simple management approach in two patients. Gastrointest Endosc 2002;56:582-4.

110.Fay DE, Luther R, Gruber M. A single procedure endoscopic technique for replacing partially extruded percutaneous endoscopic gastrotomy tubes. Gastrointest Endosc 1990;36:298-300.

111. Boyd JW, DeLegge MH, Shamburek RD, et al. The buried bumper syndrome: a new technique for safe, endoscopic PEG removal. Gastrointest Endosc 1995;41:508-11.

112.Ma MM, Semlacher EA, Fedorak RN, et al. The buried gastrostomy bumper syndrome: prevention and endoscopic approaches to removal. Gastrointest Endosc 1995;41:505-8.

113. Müller-Gerbes D, Aymaz S, Dormann AJ. Management of the buried bumper syndrome: a new minimally invasive technique--the push method. Z Gastroenterol 2009;47:1145-8.

114. Cyrany J, Repak R, Douda T, et al. Cannulotome introduced via a percutaneous endoscopic gastrostomy (PEG) tube--new technique for release of a buried bumper. Endoscopy 2012;44 Suppl 2 UCTN:E422-3.

115.Ulla JL, Alvarez V, Fernandez-Salgado E, et al. Radial 
endoscopic ultrasonography and buried bumper endoscopic solution. Surg Laparosc Endosc Percutan Tech 2007;17:201-2.

116. Wolpert LE, Summers DM, Tsang A. Novel endoscopic management of buried bumper syndrome in percutaneous endoscopic gastrostomy: The Olympus HookKnife. World J Gastroenterol 2017;23:6546-8.

117. Frascio F, Giacosa A, Piero P, et al. Another approach to the buried bumper syndrome. Gastrointest Endosc 1996;43:263.

118. Ellrichmann M, Sergeev P, Bethge J, et al. Prospective evaluation of malignant cell seeding after percutaneous endoscopic gastrostomy in patients with oropharyngeal/ esophageal cancers. Endoscopy 2013;45:526-31.

119. Sheykholeslami K, Thomas J, Chhabra N, et al. Metastasis of untreated head and neck cancer to percutaneous gastrostomy tube exit sites. Am J Otolaryngol 2012;33:774-8.

120. Khurana V, Singh T. Percutaneous endoscopic gastrostomy site metastasis in esophageal cancer. Gastrointest Endosc 2005;62:612.

121. Strodel WE, Kenady DE, Zweng TN. Avoiding stoma seeding in head and neck cancer patients. Surg Endosc 1995;9:1142-3.

122. Blumenstein I, Shastri YM, Stein J. Gastroenteric tube feeding: techniques, problems and solutions. World J Gastroenterol 2014;20:8505-24.

123. Rey JR, Axon A, Budzynska A, et al. Guidelines of the European Society of Gastrointestinal Endoscopy (E.S.G.E.) antibiotic prophylaxis for gastrointestinal endoscopy. European Society of Gastrointestinal Endoscopy. Endoscopy 1998;30:318-24.

124.American Society for Gastrointestinal Endoscopy. Antibiotic prophylaxis for gastrointestinal endoscopy. Gastrointest Endosc 1995;42:630-5.

125.Lipp A, Lusardi G. A systematic review of prophylactic antimicrobials in PEG placement. J Clin Nurs 2009; 18:938-48.

126.Lagergren J, Mattsson F, Lagergren P. Clinical

Cite this article as: Zouk $\mathrm{AN}$, Batra H. Managing complications of percutaneous tracheostomy and gastrostomy. J Thorac Dis 2021;13(8):5314-5330. doi: 10.21037/jtd-19-3716 implementation of a new antibiotic prophylaxis regimen for percutaneous endoscopic gastrostomy. BMJ Open 2013;3:e003067.

127. Blomberg J, Lagergren P, Martin L, et al. Novel approach to antibiotic prophylaxis in percutaneous endoscopic gastrostomy (PEG): randomised controlled trial. BMJ 2010;341:c3115.

128. Strijbos D, Schoon EJ, Curvers W, et al. Antibacterial gauzes are effective in preventing infections after percutaneous endoscopic gastrostomy placement: a retrospective analysis. Eur J Gastroenterol Hepatol 2016;28:297-304.

129. Galat SA, Gerig KD, Porter JA, et al. Management of premature removal of the percutaneous gastrostomy. Am Surg 1990;56:733-6.

130. Tsang TK, Eaton D, Falconio MA. Percutaneous ostomy dilation: a technique for dilating the closed percutaneous endoscopic gastrostomy sites and reinserting gastrostomies. Gastrointest Endosc 1989;35:336-7.

131.Lynch CR, Fang JC. Prevention and management of complications of percutaneous endoscopic gastrostomy (PEG) tubes. Pract Gastroenterol 2004;28:66-77.

132. Conroy T. The Prevention and Management of Complications associated with established Percutaneous Gastrostomy Tubes in Adults: A Systematic Review. JBI Libr Syst Rev 2009;7:1-37.

133. Dinh B, Chen P, Beck G. A Migrated Percutaneous Endoscopic Gastrostomy Tube Inducing Gastric Outlet Obstruction and Acute Pancreatitis: 1330. Am J Gastroenterol 2018;113:S762-3.

134. Shah J, Sunkara T, Yarlagadda KS, et al. Gastric outlet and duodenal obstruction as a complication of migrated gastrostomy tube: report of two cases and literature review. Gastroenterology Res 2018;11:71.

135. Fischer LS, Bonello JC, Greenberg E. Gastrostomy tube migration and gastric outlet obstruction following percutaneous endoscopic gastrostomy. Gastrointest Endosc 1987;33:381-2. 